\title{
Correction of Unintended Aftermath of Fixed Functional Appliance in Class II Division 1 Malocclusion - A Case Report
}

Dr. Yunus Amin ${ }^{1 *}$, Dr. Terry Thomas Edathotty ${ }^{2}$, Dr. Raja Sankeralingom ${ }^{3}$, Dr. Ratna Parameswaran ${ }^{4}$, Dr. Devaki Vijayalakshmi ${ }^{5}$, Dr. K.S.Nagachandran ${ }^{6}$

${ }^{1}$ Private Practitioner 96/8 School Street North, Alwarthirunagar Annexe, Chennai - 600087 India

${ }^{2}$ Reader Mar Baselios Dental College Thankalam Kothamangalam Cochin- 686691 India

${ }^{3}$ Private Practitioner Bharathi Dental Hospital 91 Sp Office Road East of tower Junction Nagercoil - 629001 India

${ }^{4}$ Professor Meenakshi Ammal dental college and hospital Alapakkam main road, Maduravoyal Chennai - 600095 India

${ }^{5}$ Professor and head of the department Meenakshi Ammal dental college and hospital Alapakkam main road, Maduravoyal Chennai - 600095 India

${ }^{6}$ Reader Meenakshi Ammal dental college and hospital Alapakkam main road, Maduravoyal Chennai - 600095 India

DOI: $\underline{\text { 10.36348/sjodr.2020.v05i03.007 }}$ | Received: 14.02 .2020 | Accepted: 21.02 .2020 | Published: 18.03 .2020

*Corresponding author: Dr. Yunus Amin

\section{Abstract}

The knowledge of orthodontic appliances used for correction of skeletal and dental deformities is essential for the success of orthodontic treatment. The simplest problems during the treatment phase can lead to complicated situation and solving that requires proper and thorough knowledge of its working capacity and biomechanics. The following is a case which was treated with an Orthopedic appliance (FORSUS) which lead to an unforsaken situation and treating that to achieve ideal skeletal and dental stability.

Keywords: Orthodontics, Orthopedic, Appliance, Biomechanics, Skeletal.

Copyright @ 2020: This is an open-access article distributed under the terms of the Creative Commons Attribution license which permits unrestricted use, distribution, and reproduction in any medium for non-commercial use (NonCommercial, or CC-BY-NC) provided the original author and source are credited.

\section{INTRODUCTION}

Angle's Class II is the most common malocclusion reported when compared to Class I or Class III. Research suggests that Mandibular Retrognathism is the most common underlying cause rather than maxillary prognathism [1]. It has been reported that the effectiveness of functional therapy depends on both the treatment timing (skeletal maturity at the start of functional therapy) and the type of functional appliance used [2].

Ruf and Pancherz[7,10], Konik et al. [6] and Kinzinger and Diedrich [8] stated that the treatment of late adolescents and young adults with rigid fixed functional appliances such as the Herbst or functional mandibular advancer resulted in correction of the both skeletal and dental parameters in Class II malocclusion. However, the changes produced by semi-rigid fixed functional appliances might be different from those produced with rigid devices.

Occasional incidences happen that change the phase of the routine treatment plan. This article presents a case report of an adolescent skeletal class II patient who was treated with a fixed functional appliance (FORSUS-Fatigue Resistance Device) which succumbed to an untoward reaction that was eventually treated with appropriate measures.

\section{Diagnosis and treatment planning}

A 15years old boy reported with a complaint of forwardly placed upper front teeth and a small lower jaw. Clinical examination revealed mesomorphic body type, symmetric face with an average mandibular plane angle and a marginally decreased lower facial height. $\mathrm{He}$ had a convex facial profile, a posterior divergent face and an acute nasolabial angle. Though he exhibited lip competency at rest, there was evident lip trap during the functional examination. He had acceptable smile aesthetics though incisor exposure on smile was compromised owing to severe proclination (Fig: 1).

Intra-oral examination revealed normal soft tissue. Patient presented with dentoalveolar Class II division 1 malocclusion, unilateral posterior crossbite (right, complete deep bite), increased overjet (8mm), constricted upper and lower arch forms. Examination of dentition revealed clinically missing upper and lower right second premolar in the arch with exaggerated curve of Spee. 
Visual treatment objective was found to be positive indicating the patient to be subjected to a functional appliance.

Radiographic Examination revealed Impacted upper and lower right second premolar. There was no evident dental pathology. The crown formation of all third molars was nearing completion.

\section{Cephalometric interpretation}

The lateral cephalogram showed the SNA value to be $83^{\circ}$ and SNB to be $76^{\circ}$ with an ANB value of $7^{\circ}$ signifying a skeletal Class II discrepancy primarily the result of a retrognathic mandible. The Wits appraisal of $5 \mathrm{~mm}$ corroborated this fact. Vertical skeletal evaluation revealed a mild decreasing facial height ratio and a maxillo-mandibular plane angle of $22^{\circ}$. Dental analysis showed upper incisor inclination to $\mathrm{SN}$ at $129^{\circ}$. The lower incisor to mandibular plane angle was at $101^{\circ}$, signifying a severe proclination of the maxillary and mandibular incisors. The lower incisor is ahead when evaluated against the A-Pog line by $6 \mathrm{~mm}$. The lower lip was retrusive to the aesthetic plane by $5 \mathrm{~mm}$. Cervical vertebral staging revealed deceleration. Hence the case was diagnosed as Angle's Class II division 1 malocclusion on a Class II skeletal base attributing to orthognathic maxilla and retrognathic mandible on an average mandibular plane angle with proclined and crowded upper and lower teeth, unilateral posterior crossbite, increased overjet, deep bite, impacted upper and lower right second premolar.

\section{Treatment objectives}

- Correction of soft tissue profile

- Correction of class II skeletal pattern

- Correction of retrognathic mandible

- Correction of cross bites

- Correction of deep bite \&Level the curve of spee

- Achieve a Class I incisor relationship with ideal overjet and overbite

- Achieve a Class I molar relation

- Retention with periodic reviews to monitor any relapse tendency

- Review the eruption of third molars

\section{Treatment plan}

- Impacted upper and lower right second premolar and erupted upper and lower left first premolar was extracted.

- Owing to the severe upper and lower anterior proclination, a two-phase treatment was planned which corrected the dentoalveolar component initially followed by correction of skeletal problem later.

Phase i: (pre-functional levelling, aligning and space closure)

- Fixed Preadjusted edgewise appliance with MBT prescription (MBTTM.022").

\section{Phase ii: (growth modification)}

- Functional appliance: Fixed functional (FORSUS fatigue resistant Device, 3M Unitek).

\section{Prognosis for stability}

The most important factor for maintaining the skeletal correction using growth modification procedure is the presence of a good and well interdigitated occlusion. The corrected anterior deep bite should be retained well with a good edge-centroid relationship and proper inter-incisal angle. Achievement of lip competency would aid in retaining the overjet reduction.

\section{Treatment progress}

Treatment was commenced after extraction of the premolars. Phase I treatment was started with $0.022 \mathrm{MBT}$ pre-adjusted edgewise appliance, $0.016 \mathrm{Niti}$ archwire was placed in both upper and lower arches.

Later, Archwires were upgraded to $0.016 \times 0.022$ Niti till $0.019 \times 0.025$ Niti. Once levelling and aligning was completed retraction was performed with $0.017 \times 0.025$ S.S Tear drop loop.

After space closure $0.021 \times 0.025$ Stainless Steel was placed in upper and lower arch and fixed functional appliance, FORSUS was advocated for the required skeletal correction (Fig: 2). Crimps were added bilaterally, so as to allow reactivation of FORSUS.

Once the FORSUS is engaged, it is mandatory to subject the patient to routine review (every 4weeks) to prevent any untoward reactions. However, the patient failed to report for more than 6 months which resulted in unwanted movements in the teeth (Fig: 3 ) and also a change in the condylar position which was evident in the Orthopantomograph (Fig: 4).

\section{TREATMENT RESULTS}

Following two phase treatment with FORSUS, the skeletal component of the malocclusion was successfully corrected but due to unintended effects on the dentoalveolar component, patient presented with Class III molar relation with reverse overjet, crossbite and anteriorly displaced condyle which was eventually rectified with further orthodontic intervention. 

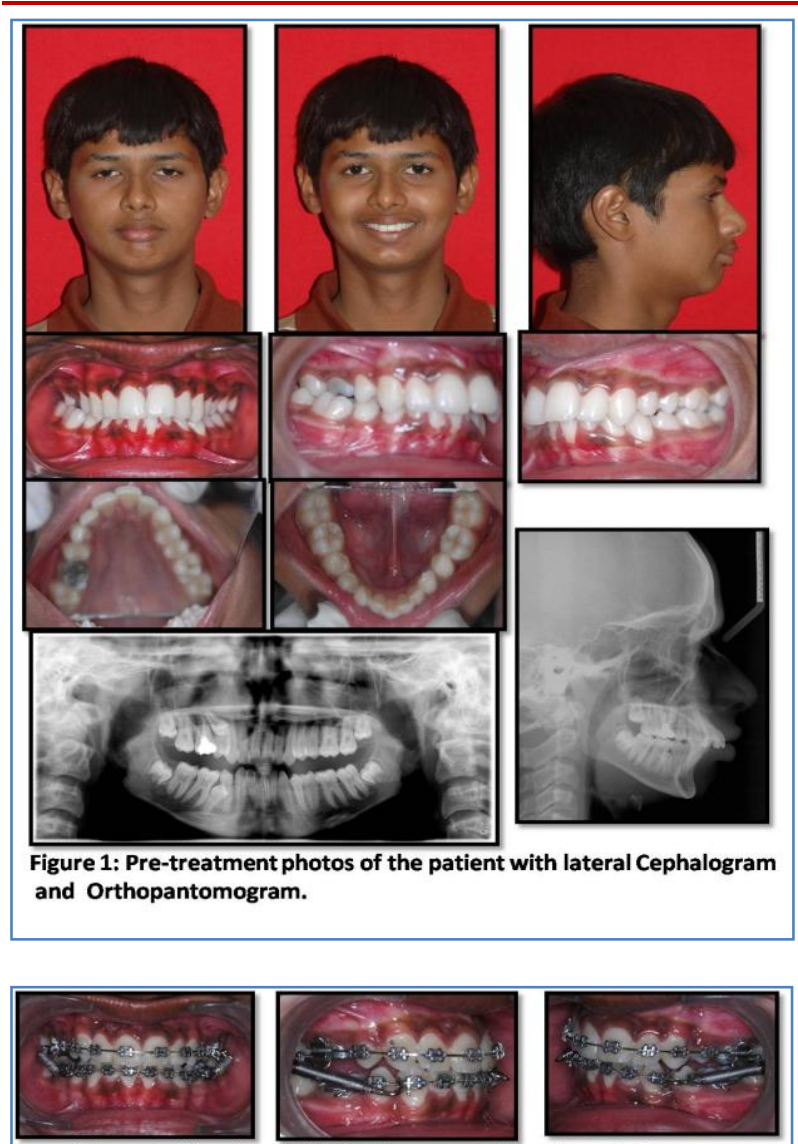

Figure 2: Showing FORSUS placement after Phase I therapy.
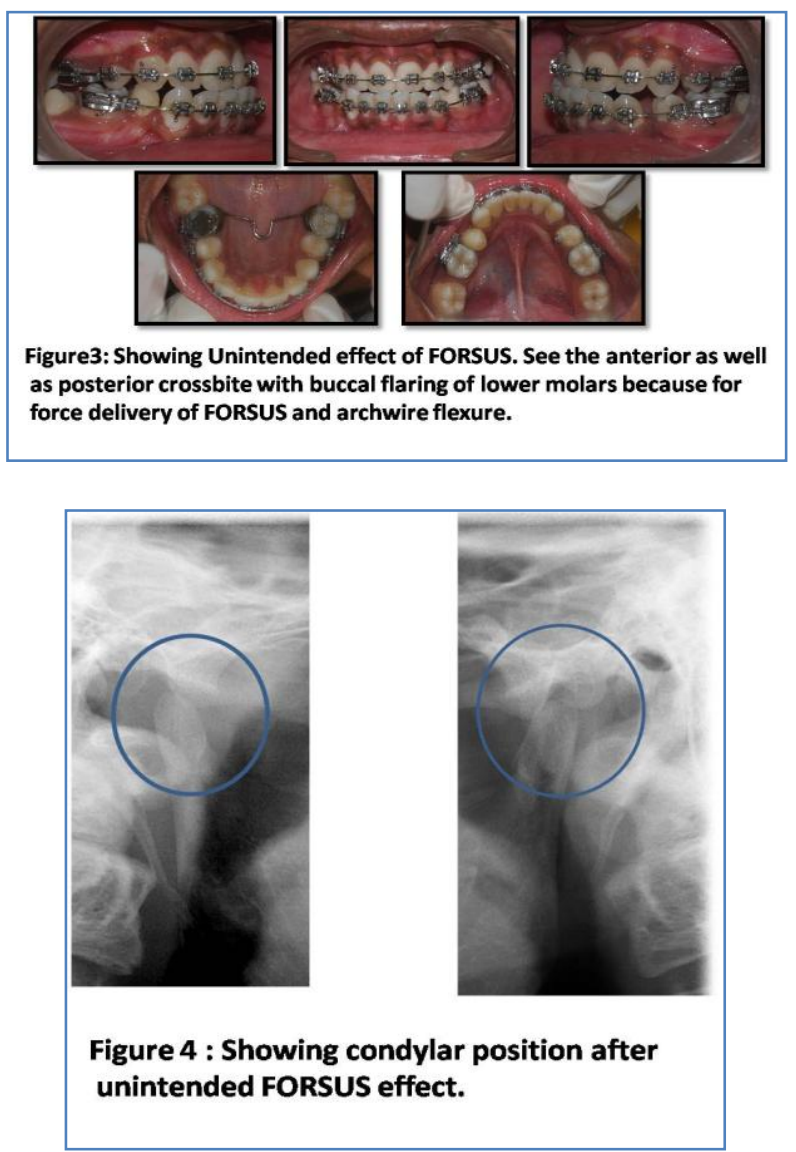

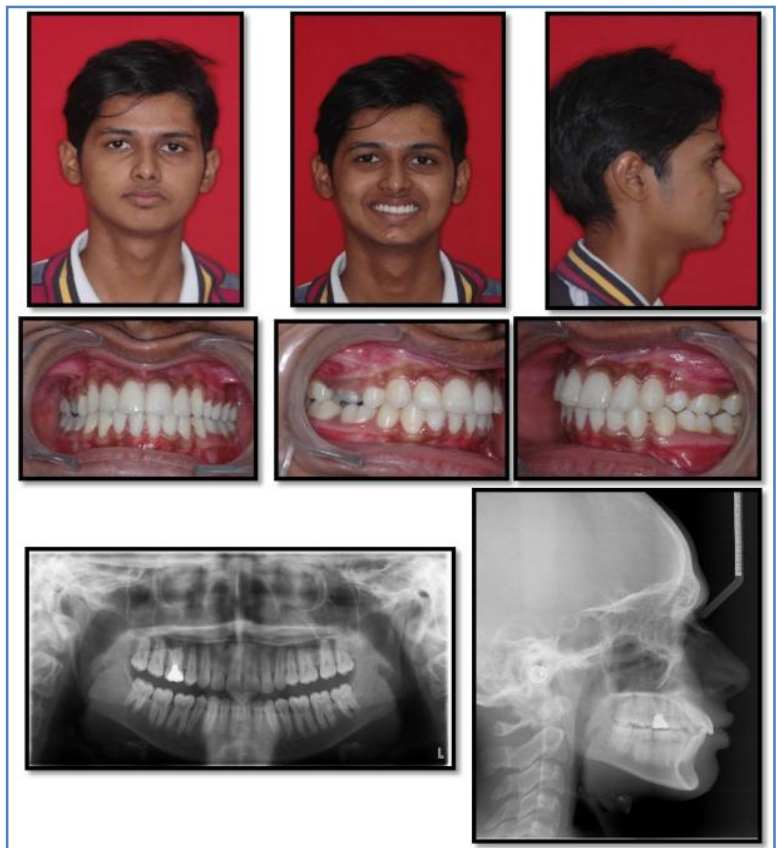

Figure 5: Post treatment photos showing good improvement in the patients profile and skeletal base.

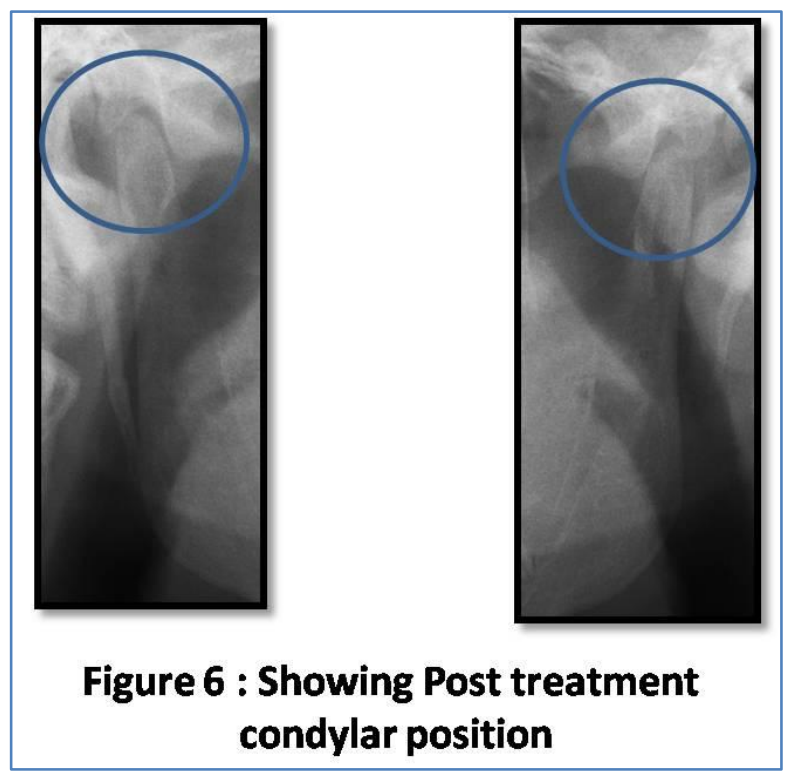

\section{DISCUSSION}

As an untoward effect, the patient presented with a Class III molar relation, with buccal rolling of lower molars creating a posterior crossbite. There was a mesial movement of the entire lower arch creating space between lower first and second molars. The lower extraction space opened bilaterally by $3 \mathrm{~mm}$, extrusion as well as lingual rolling of right lower first bicuspid occurred due to debonding of the bracket (Fig: 3). Radiographic examination revealed anterior shift of the mandible showing change in the condylar position anteriorly. Leucke and Johnston et al. [4] found that $70 \%$ of their sample had anterior condylar repositioning, whereas $30 \%$ experienced posterior condylar repositioning during orthodontic treatment. 
Though the patient's condyle was displaced anteriorly he did not complain of pain or any discomfort related to the temporomandibular joint. Shen et al. [9] in their study found that alteration in mechanical forces such as use of Class II elastics for space closure can explain how condylar resorption can occur by orthodontic mechanical force. O'reily et al. [5] had reported that usage of class II elastics have little or no effects on TMD signs and symptoms. In view of the abovementioned studies that showed class II elastics with forces that are much reduced in intensity appliance could bring about iatrogenic changes in TMJ which can lead to TMD it would be highly probable that fixed functional appliance could cause more deleterious effects on the TMJ.

Since this was a transient malocclusion which was iatrogenically created, rectifying such problems was possible since it was detected early. Greene and Laskin[3] did a questionnaire survey on TMD in growing children and concluded that symptoms of TMD are generally benign and do not progress to more serious clinical dysfunction or disease, even in subjects who previously had symptoms. Previous study stated that TMJ problems gets worsened and but in few instances it improved mainly because of the glenoid fossa remodelling that happened during growth period which tend to resolve the TMJ problems devoid of intervention, followed by correction of condylar position to its primary site (i.e.) centric relation. The adaptability of TMJ to mechanical effects varies according to age.

To overcome these deleterious effects, the FORSUS was subsequently removed and then alignment was completed with $0.019 \times 0.025 \mathrm{Niti}$ and upgraded to stainless steel wire with mild constriction in the lower arch and expansion in upper arch with crossbite elastics (through the bite elastics) to correct bilateral posterior crossbite. Class III elastics were advised for distal movement of the lower segment thereby pushing the anteriorly placed condyle relatively to its original position. Extraction space was closed followed by correction of crossbite. The iatrogenically created malocclusion was corrected in 4 months and final settling of occlusion to ideal Class I molar and canine relation was achieved using inter-maxillary elastics (Fig: 5). The condylar position was eventually restored to its ideal position before the signs and symptoms of TMD were initiated (Fig: 6).

\section{CONCLUSION}

Though treatment with fixed functional appliances yield good results in correcting skeletal class II patients, care should always be taken to prevent any adverse effects or untoward effects. When such untoward effects happen, as orthodontists we should visualize it early enough to treat the situation before it gets deteriorated. Most importantly TMJ should be considered as an important factor while dealing with orthopaedic appliances as of condylar displacement that happens during treatment can iatrogenically lead to TMDs.

\section{REFERENCES}

1. McNAMARA Jr, J. A. (1981). Components of Class II malocclusion in children 8-10 years of age. The Angle Orthodontist, 51(3), 177-202.

2. Malmgren, O., Ömblus, J., Hägg, U., \& Pancherz, H. (1987). Treatment with an orthopedic appliance system in relation to treatment intensity and growth periods A study of initial effects. American Journal of Orthodontics and Dentofacial Orthopedics, 91(2), 143-151.

3. Greene, C. S., \& Laskin, D. M. (1988). Long-term status of TMJ clicking in patients with myofascial pain and dysfunction. The Journal of the American Dental Association, 117(3), 461-465.

4. Luecke III, P. E., \& Johnston Jr, L. E. (1992). The effect of maxillary first premolar extraction and incisor retraction on mandibular position: testing the central dogma of "functional orthodontics". American Journal of Orthodontics and Dentofacial Orthopedics, 101(1), 4-12.

5. O'Reilly, M. T., Rinchuse, D. J., \& Close, J. (1993). Class II elastics and extractions and temporomandibular disorders: a longitudinal prospective study. American Journal of Orthodontics and Dentofacial Orthopedics, 103(5), 459-463.

6. Konik, M., Pancherz, H., \& Hansen, K. (1997). The mechanism of Class II correction in late Herbst treatment. American journal of orthodontics and dentofacial orthopedics, 112(1), 87-91.

7. Ruf, S., \& Pancherz, H. (1999). Dentoskeletal effects and facial profile changes in young adults treated with the Herbst appliance. The Angle Orthodontist, 69(3), 239-246.

8. Kinzinger, G., \& Diedrich, P. (2005). Skeletal effects in class II treatment with the functional mandibular advancer (FMA)?. Journal of Orofacial Orthopedics/Fortschritte der Kieferorthopädie, 66(6), 469-490.

9. Shen, Y. H., Chen, Y. K., \& Chuang, S. Y. (2005). Condylar resorption during active orthodontic treatment and subsequent therapy: report of a special case dealing with iatrogenic TMD possibly related to orthodontic treatment. Journal of oral rehabilitation, 32(5), 332-336.

10. Ruf, S., \& Pancherz, H. (2006). Herbst/multibracket appliance treatment of Class II division 1 malocclusions in early and late adulthood. A prospective cephalometric study of consecutively treated subjects. The European Journal of Orthodontics, 28(4), 352-360. 